NASA/TM-2004-212952
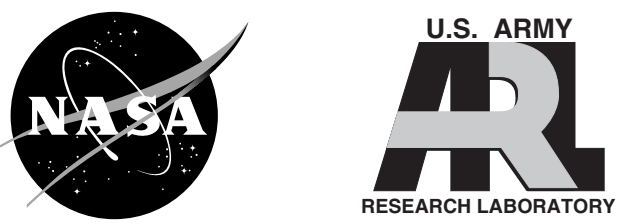

High Speed, High Temperature, Fault Tolerant Operation of a Combination Magnetic-Hydrostatic Bearing Rotor Support System for Turbomachinery

Mark Jansen

University of Toledo, Toledo, Ohio

Gerald Montague

U.S. Army Research Laboratory, Glenn Research Center, Cleveland, Ohio

Andrew Provenza

Glenn Research Center, Cleveland, Ohio

Alan Palazzolo

Texas A\&M University, College Station, Texas 
Since its founding, NASA has been dedicated to the advancement of aeronautics and space science. The NASA Scientific and Technical Information (STI) Program Office plays a key part in helping NASA maintain this important role.

The NASA STI Program Office is operated by Langley Research Center, the Lead Center for NASA's scientific and technical information. The NASA STI Program Office provides access to the NASA STI Database, the largest collection of aeronautical and space science STI in the world. The Program Office is also NASA's institutional mechanism for disseminating the results of its research and development activities. These results are published by NASA in the NASA STI Report Series, which includes the following report types:

- $\quad$ TECHNICAL PUBLICATION. Reports of completed research or a major significant phase of research that present the results of NASA programs and include extensive data or theoretical analysis. Includes compilations of significant scientific and technical data and information deemed to be of continuing reference value. NASA's counterpart of peerreviewed formal professional papers but has less stringent limitations on manuscript length and extent of graphic presentations.

- TECHNICAL MEMORANDUM. Scientific and technical findings that are preliminary or of specialized interest, e.g., quick release reports, working papers, and bibliographies that contain minimal annotation. Does not contain extensive analysis.

- CONTRACTOR REPORT. Scientific and technical findings by NASA-sponsored contractors and grantees.
- CONFERENCE PUBLICATION. Collected papers from scientific and technical conferences, symposia, seminars, or other meetings sponsored or cosponsored by NASA.

- SPECIAL PUBLICATION. Scientific, technical, or historical information from NASA programs, projects, and missions, often concerned with subjects having substantial public interest.

- TECHNICAL TRANSLATION. Englishlanguage translations of foreign scientific and technical material pertinent to NASA's mission.

Specialized services that complement the STI Program Office's diverse offerings include creating custom thesauri, building customized databases, organizing and publishing research results ... even providing videos.

For more information about the NASA STI Program Office, see the following:

- Access the NASA STI Program Home Page at http://www.sti.nasa.gov

- E-mail your question via the Internet to help@sti.nasa.gov

- Fax your question to the NASA Access Help Desk at 301-621-0134

- Telephone the NASA Access Help Desk at 301-621-0390

- Write to:

NASA Access Help Desk

NASA Center for AeroSpace Information 7121 Standard Drive

Hanover, MD 21076 
NASA/TM-2004-212952
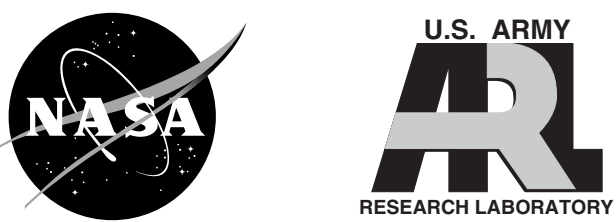

\section{High Speed, High Temperature, Fault Tolerant Operation of a Combination Magnetic-Hydrostatic Bearing Rotor Support System for Turbomachinery}

Mark Jansen

University of Toledo, Toledo, Ohio

Gerald Montague

U.S. Army Research Laboratory, Glenn Research Center, Cleveland, Ohio

Andrew Provenza

Glenn Research Center, Cleveland, Ohio

Alan Palazzolo

Texas A\&M University, College Station, Texas

Prepared for the

Turbo Expo 2004

sponsored by the American Society of Mechanical Engineers

Vienna, Austria, June 14-17, 2004

National Aeronautics and

Space Administration

Glenn Research Center 
This report is a preprint of a paper intended for presentation at a conference. Because of changes that may be made before formal publication, this preprint is made available with the understanding that it will not be cited or reproduced without the permission of the author.

Trade names or manufacturers' names are used in this report for identification only. This usage does not constitute an official endorsement, either expressed or implied, by the National Aeronautics and Space Administration.

Available from

NASA Center for Aerospace Information 7121 Standard Drive

Hanover, MD 21076
National Technical Information Service 5285 Port Royal Road Springfield, VA 22100 


\title{
HIGH SPEED, HIGH TEMPERATURE, FAULT TOLERANT OPERATION OF A COMBINATION MAGNETIC-HYDROSTATIC BEARING ROTOR SUPPORT SYSTEM FOR TURBOMACHINERY
}

\author{
Mark Jansen \\ University of Toledo \\ Toledo, Ohio 43606 \\ Gerald Montague \\ U.S. Army Research Laboratory \\ Glenn Research Center \\ Cleveland, Ohio 44135 \\ Andrew Provenza \\ National Aeronautics and Space Administration \\ Glenn Research Center \\ Cleveland, Ohio 44135 \\ Alan Palazzolo \\ Texas A\&M University \\ College Station, Texas 77843
}

\begin{abstract}
Closed loop operation of a single, high temperature magnetic radial bearing to 30,000 RPM (2.25 million DN) and $540^{\circ} \mathrm{C}\left(1,000^{\circ} \mathrm{F}\right)$ is discussed. Also, high temperature, fault tolerant operation for the three axis system is examined. A novel, hydrostatic backup bearing system was employed to attain high speed, high temperature, lubrication free support of the entire rotor system. The hydrostatic bearings were made of a high lubricity material and acted as journal-type backup bearings. New, high temperature displacement sensors were successfully employed to monitor shaft position throughout the entire temperature range and are described in this paper. Control of the system was accomplished through a stand alone, high speed computer controller and it was used to run both the fault-tolerant PID and active vibration control algorithms.
\end{abstract}

\section{INTRODUCTION}

In 1998, several goals were set forth by NASA's Environmental Compatibility Assessment Team. They were to: "reduce emissions of future aircraft by a factor of three within 10 years, and a factor of five within 20 years", "reduce the perceived noise levels of future aircraft by a factor of two from today's subsonic aircraft within 10 years, and by a factor of four within 20 years", "maintain superiority of US aircraft and engines", "improve safety, efficiency, and cost effectiveness of global air transport systems", and "ensure long-term environmental compatibility of aviation systems". These goals must be met without a sacrifice in safety or an increase in the cost of transportation (1).

These objectives are pushing current turbine engines to their limits, both in speed and temperature. In order to reach the goals set forth by NASA, the military, and the aircraft industry, radical new engine designs are required. Magnetic bearings are one cutting edge technology that will allow engines to operate at speeds and temperatures well beyond the limits of current technologies. Thus, smaller, quieter, lighter, more efficient engines can be realized, resulting in lower operating costs, higher reliability, and fewer emissions.

Current engine systems are supported by ball bearings and dampers, which are limited in speed $(<2$ million DN) and temperature $<260^{\circ} \mathrm{C}\left(<500^{\circ} \mathrm{F}\right)$. Additionally, these systems require complicated secondary cooling paths and an intricate lubrication system. These components significantly increase the weight, complexity, and cost of the aircraft.

Magnetic bearings provide a unique, smart component solution to this problem. Since there are no contacting parts in a magnetic bearing, the lubrication system can be eliminated. Because the magnetic bearing can operate at extreme temperatures, the secondary cooling air can also be eliminated. Another advantage of the magnetic bearing is that the shaft can be operated at much higher speeds with significantly lower power usage when compared to conventional ball bearing losses (2) and (12).

With the elimination of the lubrication system, maintenance costs will be lower due to a less complicated system, no need to store or dispose of hazardous materials, and elimination of spill and contamination issues during service. These savings can add up to billions of dollars over the service life of a fleet of aircraft. The removal of the lubrication system will also lower emissions from the engine and make the engine more fire safe.

Another limitation overcome with magnetic bearings is that of fatigue life. In a conventional rolling element bearing system, bearings suffer from fatigue, which at high speeds can require replacement of bearings in a relatively short amount of time. Since there are no contacting parts in magnetic bearings, raceway fatigue is not an issue. 
Magnetic bearings also offer several advantages over other non-contacting type bearings, such as journal and foil bearings. First, magnetic bearings are able to support a rotor at zero speed, thus eliminating touchdowns during startup and shutdown and the need for lubrication during these events. Also, magnetic bearings do not need a fluid to operate, making them suitable to operate at extreme altitudes, in vacuum, or with a highly viscous fluid. Additionally, magnetic bearings have full force capacity throughout the entire operating range, independent of speed and fluid density.

However, in many applications journal or foil bearings provide an excellent solution for backup or touchdown bearings for a magnetic bearing system. Since these types of bearings are also non-contacting, they can operate at the high speeds and temperatures that can be achieved with magnetic bearings. These types of bearings can provided a good backup system in case of total magnetic bearing failure (i.e. power loss) or for sudden, short load sharing, such as an aircraft carrier landing.

Magnetic bearings also provide an active rotor support system. This is an advantage for adapting or actively responding to transient events such as a hard aircraft landing, blade rubs, or sudden imbalances (such as a blade loss). Another advantage of an active rotor support system is that blade tip clearance can be controlled to prevent the onset of compressor stall or surge resulting in increased operating margins. A third advantage of the system is that it allows for active health monitoring of the rotor support system. This will help reduce maintenance costs by giving a technician information about the system without even having to open an access panel.

Preliminary system studies have show that a magnetic bearing system weighs significantly less $(\sim 5 \%)$ than an equivalent oil lubricated bearing system (3). These weight savings, in addition to higher power density, reduced maintenance and more efficient engines, will also contribute to significant overall fleet savings.

First introduced in an ultracentrifuge rotor in the 1930s (4), magnetic bearings are not a new concept. However, only recently has the technology been developed to a level which is suitable for the extreme temperature environments required by the next generation of turbine engines. Advancements in magnetic materials with good mechanical and magnetic properties, high temperature sensor and coil technology, and inexpensive, powerful computers and power supplies have put magnetic bearing technology on the forefront for the next generation of advanced gas turbines.

Previous work done by others (5) to (9) laid the groundwork for the research that has been conducted at NASA Glenn Research Center. These works tested material's magnetic and mechanical properties, provided a foundation for control schemes used in this facility, and described some operation at elevated temperature and high speeds.

Previously, the authors (10) to (13) have successfully operated the magnetic bearing described in this paper at high speeds and temperatures while measuring force capacity and power usage. The focus of this work is to continue the previous research and demonstrate levitation operation of the magnetic bearing to $30,000 \mathrm{RPM}$ and $540^{\circ} \mathrm{C}\left(1,000^{\circ} \mathrm{F}\right)$ and implement a novel, hydrostatic backup rotor support system.

\section{PREVIOUS FACILITY CONFIGURATION}

The facility used for this experiment is shown in Figure 1 and Figure 2. A single radial magnetic bearing is located at the center of gravity of the shaft. The magnetic bearing stator is an isolated, modular C-core, 12-pole, heteropolar design. The width of the stator is $76.1 \mathrm{~mm}$ (3.4 in.) and supports a $75 \mathrm{~mm}$ (2.97 in.) diameter rotor. Each C-core consists of two poles, each wrapped with a specialty wire. This pure silver wire has a patent-pending, high-temperature insulation process that allows for the maximum packing factor (amount of wire/given volume) and is more fully described in Reference (13). Because of the high packing factor, the bearing force is maximized and the special insulation allows for high temperature operation.

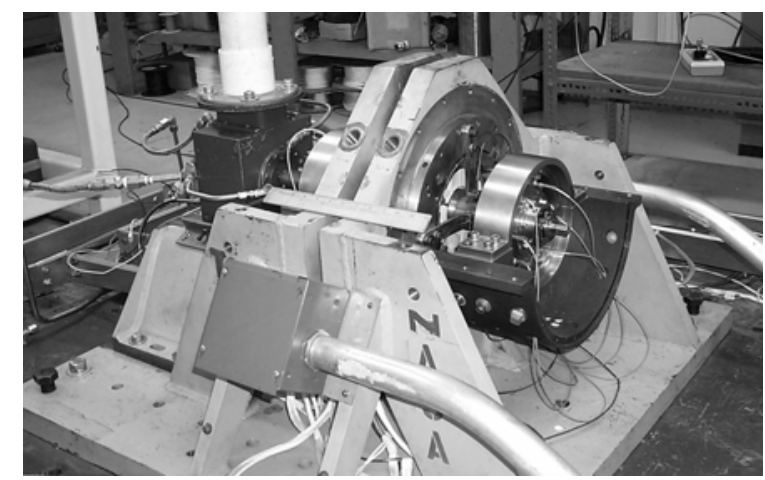

Figure 1 - High temperature magnetic bearing test facility at NASA Glenn Research Center

Power is provided through filtered, tri-state, pulse width modulated (PWM) amplifiers and heat is supplied by three band heaters wrapped around the stator. The magnetic bearing design is fully described in Reference (13).

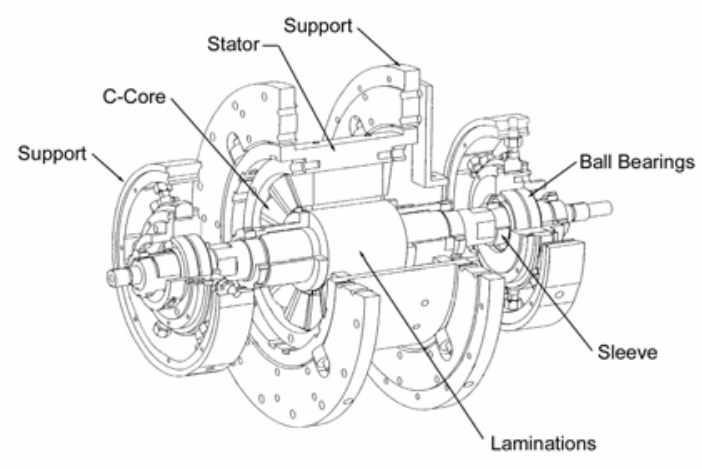

Figure 2 - Schematic of high temperature magnetic bearing facility. 
The rotor is supported at either end by a unique, interchangeable rotor support system. This system includes a support bearing and a sleeve, which is pressed onto the end of the shaft. The type of support bearings used can be changed and the sleeve diameter can be varied in size to provide a clearance or interference fit with the support bearings. For reference, the sensors and bearings that are closest to the air turbine drive are termed the 'inboard' and those located on the side furthest from the air turbine are referred to as the 'outboard'.

For the load tests described in Reference (10) to (12), a duplex set of ball bearings with a zero clearance sleeve was used on either end. This allowed for direct measurement of load capacity as a function of speed, current, and temperature. Several configurations for the auxiliary rotor support system were used for the adaptive control tests and are fully described within this paper.

\section{FACILITY CONFIGURATION AND EXPERIMENTAL WORK}

\section{HIGH TEMPERATURE SENSORS}

In order to successfully control a levitated shaft, its position within the stator must be known. Since there was only an average of $0.559 \mathrm{~mm}(0.022 \mathrm{in})$ radial clearance between the rotor and the stator, sensor accuracy was important. Also, different thermal growth rates of the shaft and stator were a major concern. Since the sensors are not integrated into the stator, axial positioning of the sensors was also an important consideration.

Commercially available, induction based, high temperature position probes manufactured by Kaman Instrumentation were selected for this application. These sensors were developed to measure the runout of steam turbine shafts in nuclear reactors. The sensors use a special symmetrical coil design which can compensate for temperature from $25^{\circ} \mathrm{C}\left(77^{\circ} \mathrm{F}\right)$ to $540^{\circ} \mathrm{C}$ $\left(1,000^{\circ} \mathrm{F}\right)$. These sensors are also unaffected by most corrosive gases and liquids and most other environmental contaminants such as oil, dirt, radiation, and stray RF and magnetic fields (14).

The sensors have a resolution of $0.00075 \mathrm{~mm}(30 \mu \mathrm{in})$ with a sensitivity of $2.04 \mathrm{mV} / \mu \mathrm{m}(50 \mathrm{mV} / 0.001 \mathrm{in}$. $)$. The sensors have zero shift of $0.054 \% /{ }^{\circ} \mathrm{C}\left(0.03 \% /{ }^{\circ} \mathrm{F}\right) \mathrm{FSO}$ and can operate to $34 \mathrm{MPa}$ (5,000 PSI). The robustness of these sensors makes them an ideal choice for this application and eventual usage in a gas turbine environment.

In order to accommodate shaft growth due to thermal expansion, a dual sensor setup was used for each of the two fixed axes. In this configuration, two sensors are mounted $180^{\circ}$ apart. For control, the average value of the difference between the sensors is used, which compensates for thermal growth. Two planes of four sensors, located just outside the stator housing, are used to determine the feedback position of the shaft. Axis values in each plane were summed and then averaged between planes in order to accommodate tilt and give an accurate representation of the position directly at the magnetic bearing center.

The eight sensor configuration coupled with the accuracy and robustness of the sensors proved for a reliable and stable system across the entire temperature and speed range.

\section{CLOSED LOOP CONTROL}

Closed loop control was accomplished using a highspeed, real time controller. The controller employs a proportional/derivative controller with an integral option. The integrator can be switched on or off during operation. The user has control over various bearing parameters such as stiffness, damping, and integration rate. The user can also set the $\mathrm{X}$ and $\mathrm{Y}$ position of the center of rotation, set excitation (whirl) rate and amplitude, and adjust imbalance compensation parameters.

The closed loop architecture starts with the high temperature, inductive sensors monitoring the rotor's position. The sensors are attached to individual signal conditioning units that output an analog signal. After passing through a gain offset board, the signals pass through a group of circuits that subtract and average them into their respective $\mathrm{X}$ and $\mathrm{Y}$ control components. These two remaining signals are then sent through anti-aliasing filters.

The analog position signals then go to a high speed, real time controller, where they are converted to digital signals using the controller's 16-bit analog to digital (A/D) converter. The controller reads the position of the rotor and then generates the appropriate output signals to drive the PWM amplifiers. These signals are converted to analog signals using the controller's 14-bit digital to analog (D/A) converter and the passed through smoothing filters.

The control signals set the ampere output of the PWM amplifiers. The output of the amplifiers passes through another low-pass filter and then to a C-core, creating a north-pole and south-pole flux path. This creates an attractive force between the lamination stack and the $\mathrm{C}$-core.

The controller has a loop time of $25 \mu \mathrm{s}$, which equates to a control frequency of $40 \mathrm{KHz}$. The loop time was the minimum achievable with the current hardware. Loop time was minimized in order to maximize bearing's control (updates of currents and positions in a given time). The loop time achieved provided ample bandwidth to provide accurate, precise rotor control. The controller has four modes of operation: stable rotor levitation, $\mathrm{X}$ rotor position control, $\mathrm{Y}$ rotor position control, and a rotor whirl function.

With the whirl function, the user has control over the frequency and amplitude of whirl. The user can also turn on and off each axis, yielding three whirl patterns: a horizontal vibration, a vertical vibration, and a circular whirl. This part of the controller was used to demonstrate the extreme accuracy of the magnetic bearing to move the center of rotation within the backup bearing clearance throughout its entire speed and temperature range. The whirl was also used to simulate touchdown events on the backup bearings.

Another feature incorporated into the controller is a feedforward control function. Feed forward control refers to a method where the magnetic bearing is used to counter-act rotor imbalance forces. Based on the synchronous vibration component, the controller superimposes a signal onto the basic control signal to energize the appropriate $\mathrm{C}$-cores to generate a counter-acting force. When the feed forward control is active, the shaft displacement due to imbalance can be completely eliminated. Examples of both whirl and feed forward control are shown later in this paper. 


\section{LEVITATION CONFIGURATION}

The first set of tests conducted demonstrated the control authority of the magnetic bearing. To demonstrate the ability of the bearing to successfully maintain the rotor position while it is levitated and rotated, the outboard sleeve was replaced with a clearance sleeve. The clearance sleeve had a $0.254 \mathrm{~mm}$ (0.010 in.) radial clearance between it and the backup bearings, which is half of the gap between the rotor and the stator in the magnetic bearing. This gap was chosen so the shaft could coast down on the backup bearings without damaging the magnetic bearing in case of failure or magnetic bearing shutdown.

A high-speed data acquisition system monitored C-core currents, backup bearing temperatures, rotor position, and magnetic bearing temperatures. Test conditions were an operating speed to $25,000 \mathrm{RPM}$ and temperatures to $540^{\circ} \mathrm{C}$ $\left(1,000^{\circ} \mathrm{F}\right)$. During these tests, the magnetic bearing had complete and precise control over the shaft and that magnetic bearings compensated for shaft imbalance at extreme temperatures.

The first test showed the successful implementation of feed forward control, which is explained earlier in this paper. At 10,000 RPM, the shaft had synchronous vibration RMS amplitude of $\pm 51 \mu \mathrm{m}$ ( $0.002 \mathrm{in}$.) without feed forward control on. When feed forward control was activated, the shaft RMS vibration amplitude was $< \pm 6 \mu \mathrm{m}$ (0.0002 in.), a $400 \%$ reduction. Successful feed forward compensation was demonstrated to 25,000 RPM.

The next set of tests were designed to demonstrate that the magnetic bearing had precise control over the shaft's center of rotation and could move that center within the backup bearing clearance. The first test indicated that the bearing was able to displace the center of rotation by a fixed amount. This is shown in Figure 3, where the center of rotation was moved from the $(0,0)$ position to two other locations and then returned to the $(0,0)$ coordinates. The bearing was able to maintain the shaft's orbital profile of $< \pm 13 \mu \mathrm{m}$ (0.0005 in.) diameter during the shaft's center movement.

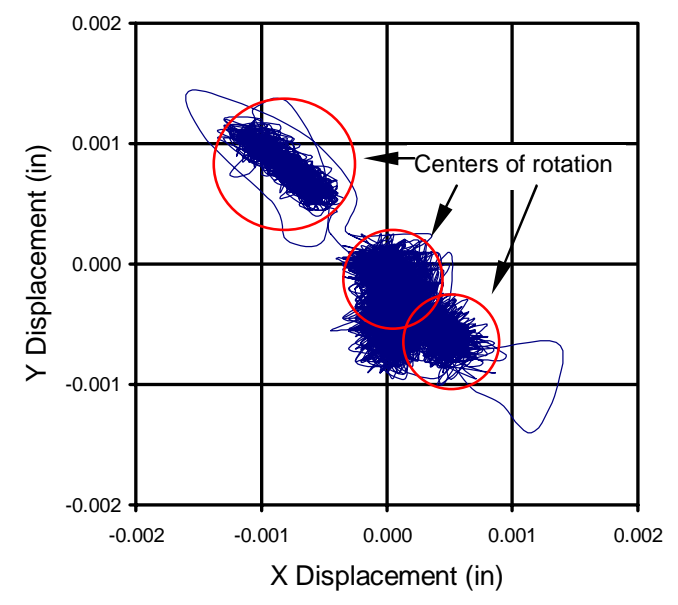

Figure 3 - Demonstration of magnetic bearings ability to move center of rotation $(25,000 \mathrm{RPM})$
The controller's $\mathrm{X}$ and $\mathrm{Y}$ displacement and whirl functions were used to move the center of the shaft $\pm 102 \mu \mathrm{m}$ ( $\pm 0.004 \mathrm{in}$.) at various frequencies up to several hundred cycles per second.

Figure 4 shows an example of the whirl function with both the $\mathrm{X}$ and $\mathrm{Y}$ displacements on. The orbit starts at the $(0,0)$ position and then the whirl function was turned on with a radius of $102 \mu \mathrm{m}$ (0.004 in.). The bearing maintained this orbit and then returned the shaft to the center position when the whirl function was turned off.

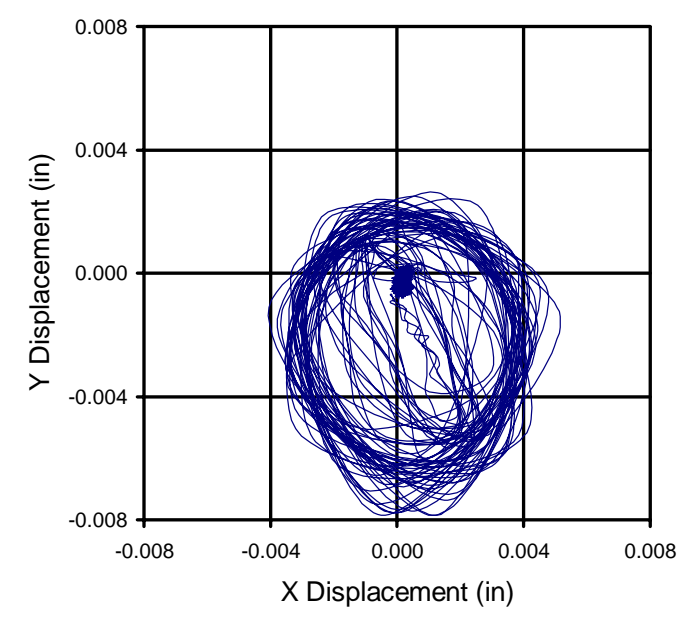

Figure 4 - Example of magnetic bearing's whirl function and center position control

\section{FAULT TOLERANT TESTING}

The next series of tests demonstrated the magnetic bearings ability to function in case of a failure in one of the C-cores. The same configuration for the backup bearings was used as in the levitation control tests.

This radial magnetic bearing was designed to have three control axes: one horizontal and two sixty degrees off vertical (Figure 5). The control algorithm was modified to include a t-matrix control method, modeled after a scheme developed in industry and further developed at Texas A\&M University and NASA GRC (15) and (16). In this control scheme, matrices of coefficients are pre-calculated and designed to make the bearing operate with only two axes, but with similar dynamic properties as the un-failed, fully populated bearing. The original output of the controller is multiplied by the matrix coefficients to adjust the control currents to the appropriate values for two axis control. For this application, only three matrices were required, one for each failed axis case.

In this implementation of the t-matrix method, the controller continuously monitors three manually controlled TTL inputs that indicate a failure of a C-core in one of the three control axes. The controller would register which C-core axis failed and then switch to the appropriate t-matrix for that failed axis case. The bearing would reach stable operation almost immediately and then operate the four remaining $\mathrm{C}$-cores for several minutes. The failed axis was then 
reactivated and the controller switched back to the original three axis configuration. Stable rotor levitation was demonstrated to $25,000 \mathrm{rpm}$ and to $540^{\circ} \mathrm{C}\left(1,000^{\circ} \mathrm{F}\right)$ with any one of the three axes failed.

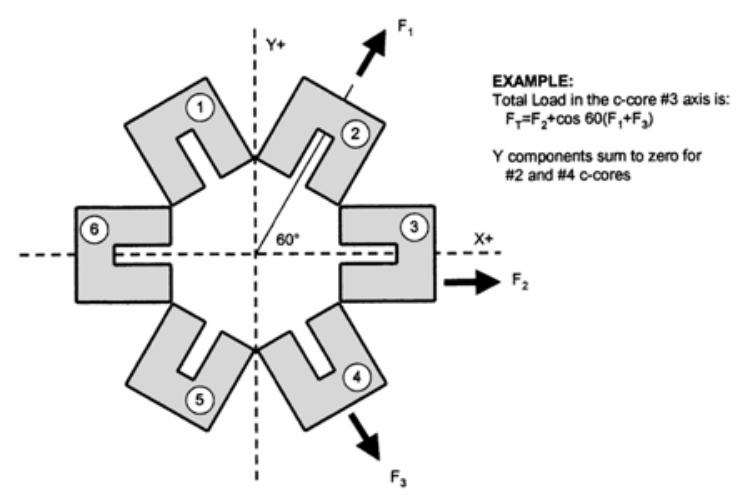

Figure 5 - High temperature magnetic bearing axis configuration

Experimental data for $\mathrm{C}$-core current and $\mathrm{X} / \mathrm{Y}$ position as a function of time is shown in Figure 6. Here, the rotor speed was $20,000 \mathrm{RPM}$ and the stator $540^{\circ} \mathrm{C}\left(1,000^{\circ} \mathrm{F}\right)$. At approximately 0.023 seconds, the 3-6 axis (see Figure 5) was shut off. The controller instantly switches to the appropriate failure matrix and accordingly adjusts the outputs to the remaining four $\mathrm{C}$-cores. As seen in the position signal, the total disturbance in the position of the rotor is less than $13 \mu \mathrm{m}$ (0.0005 in.) and it returns to the original orbit position in less than 0.04 seconds. Similar results were obtained over the entire speed and temperature range for failures in all three axes.

\section{HYDROSTATIC BEARING DESIGN AND FACILITY CONFIGURATION}

Due to the test time limitations encountered at high speeds or temperatures using the ball bearing to support the drive end, an alternate rotor support system was designed. It was clear that a non-contacting bearing would have to be used since the ball bearings were quickly overheating at high speeds and temperatures.

A unique hydrostatic bearing was thus designed to overcome this limitation. The bearing needed to meet the following criteria: a fairly large radial clearance to allow room for the magnetic bearing to actuate the shaft, high temperature capacity, low friction in case of a touchdown event, capable of harsh environmental operation, and load capacity at low or zero speed. A hydrostatic configuration was chosen over a simple journal because of load capacity at zero speed and its simplicity and low cost when compared to other non-contacting bearings (17) and (18).

A solid journal made from a high lubricity, high temperature material $\left(\right.$ Graphalloy $^{\circledR}$ ) was chosen as the basis for the bearing. This material was suitable for operation at high temperature $\left(540^{\circ} \mathrm{C}\left(1,000^{\circ} \mathrm{F}\right)\right)$, in a vacuum, or submersed in or in contact with hostile liquids and gases. One main advantage of making the entire journal from a high lubricity, solid material was that it provided a low friction rub surface throughout out its life, regardless of wear. Another advantage was that no additional surface coatings or lubricants were required for low friction operation.

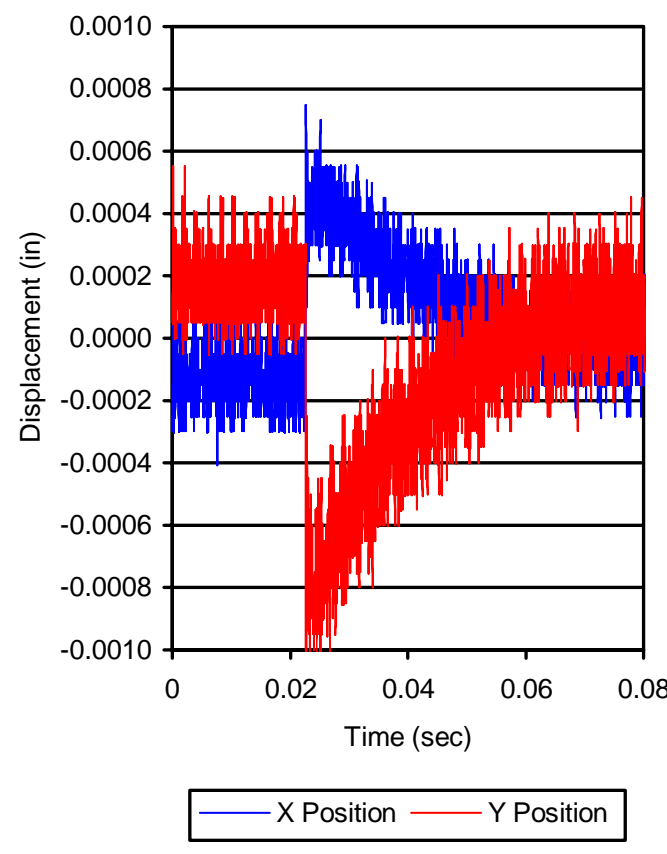

(a)

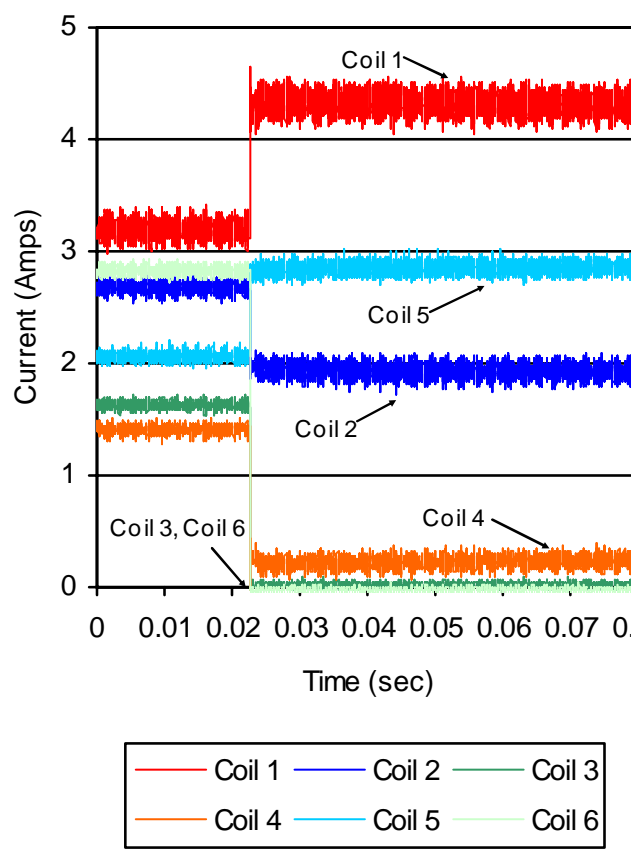

(b)

Figure 6 - Position (a) and current (b) values for fault tolerant test at $20,000 \mathrm{RPM}$ and $540^{\circ}\left(1,000^{\circ} \mathrm{F}\right)$ 
The journal used was $35.2 \mathrm{~mm}$ (1.388 in.) long with an inside diameter of $35.049 \mathrm{~mm}$ (1.3799 in.). A radial gap of $0.038 \mathrm{~mm}(0.0015 \mathrm{in}$.) existed between the hydrostatic bearing and the shaft sleeves. The basic journal bearing was modified with air supply orifices to add a hydrostatic component to the bearing. In the interest of maximum load capacity, the design went through many iterations in size and orientation. A final configuration of eight straight, $0.81 \mathrm{~mm}$ (0.032 in.) diameter through holes located axially in the center of the bearing was chosen. The journal was fit inside a housing which had an air supply channel behind the orifices. This assembly was then press fit into an outer housing, which mounted to the rig hardware and the supply air source. The bearing is shown in Figure 7.

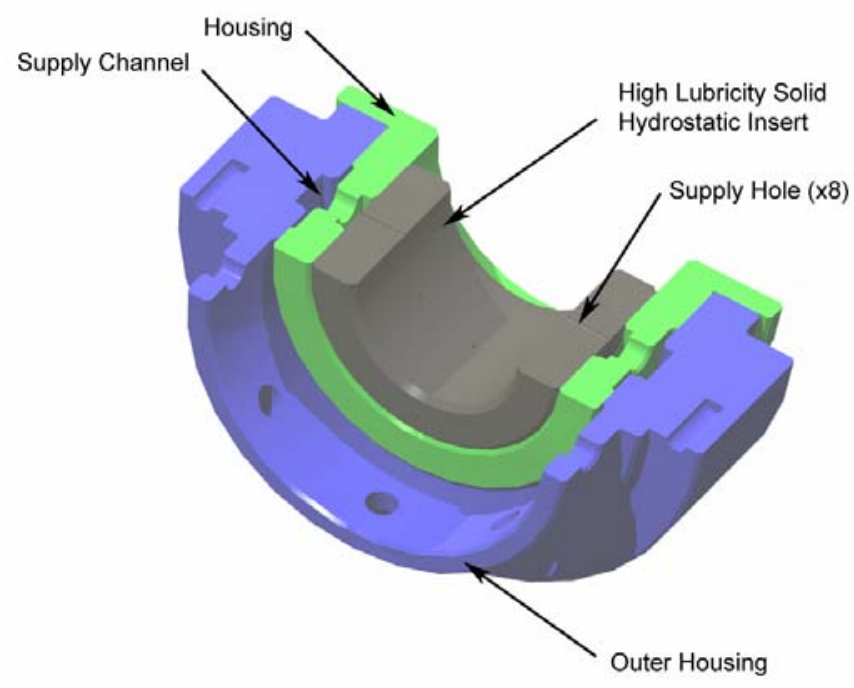

Figure 7 - Detail of hydrostatic journal bearing

Since there was a large radial gap between the rotor and the hydrostatic bearings, several air supply pressures (between $34 \mathrm{KPa}$ (5 PSI) and $758 \mathrm{KPa}(110 \mathrm{PSI})$ ) were tested without the magnetic bearing on. Shaft liftoff occurred at approximately $310 \mathrm{KPa}$ (45 PSI). It was chosen to operate the bearings at the maximum (758 $\mathrm{KPa}(110 \mathrm{PSI})$ ) pressure to try to achieve the maximum load capacity. In the final facility configuration, two hydrostatic bearings were used, one at each end.

With the two hydrostatic bearing configuration, the shaft was fully suspended radially on non-contacting bearings. A high precision, high speed coupling was used between the end of the shaft and the air turbine drive. The low stiffness coupling was used to retain the shaft axially, but did not provide radial support to the drive end of the shaft. The rotor sleeves used with hydrostatic bearings had shoulders machined on them. These contact the edge of the hydrostatic bearing in case of an axial restraint failure. In this setup, shaft, bearing, and drive system alignment was critical. The centers of the three bearings had to be aligned so stable rotation could be achieved. However, by using the magnetic bearing controller, the center of rotation of the magnetic bearing could be adjusted. This is described later in this section.

The first test in this configuration was to find out the stable operating range of the hydrostatic bearings alone. A supply pressure of $758 \mathrm{KPa}$ (110 PSI) was used at both ends of the shaft and provided the stable operation. The facility was operated with the magnetic bearing off until the sensors indicated the shaft orbit was equal to the diametric clearance and the hydrostatic bearings began to increase in temperature. This indicated touchdown or rubbing between the shaft and the journal. This was defined as the maximum speed the hydrostatic bearings would operate without magnetic bearing and occurred at approximately 4,500 RPM.

The second series of tests were to operate with the magnetic bearing active. For this case, the average value of the inboard and outboard sensors was used for the closed loop control and gave the position directly. This provided the most stable operation. Bearing C-core currents, hydrostatic bearing temperatures, and stator temperatures were monitored throughout the tests. Since perfect alignment between all the elements of the system was impossible, the magnetic bearing was used to move the shaft's center until the magnetic bearing forces were minimized (i.e., low current usage and fluctuations). Once this was established, the stiffness, damping, and bias values of the magnetic bearing were adjusted to optimize control.

Once the system was successfully operated in the low speed range $(<5,000 \mathrm{RPM})$ at room temperature and with magnetic bearing values optimized, the shaft speed was slowly increased to the target of 30,000 RPM. As the speed increased, stiffness, damping, and feed forward parameters were manually adjusted to minimize the orbit diameter and rotor vibrations. The bearing was successfully operated to 30,000 RPM without touchdown or rubbing on the backup bearings.

The next tests were performed at $540^{\circ} \mathrm{C}\left(1,000^{\circ} \mathrm{F}\right)$. The same procedure was taken to establish the operational speed without the magnetic bearing and to optimize the stiffness and damping values of the magnetic bearing. Again, the bearing was successfully operated to $30,000 \mathrm{RPM}$ at $540^{\circ} \mathrm{C}\left(1,000^{\circ} \mathrm{F}\right)$. $\mathrm{C}$-core current, hydrostatic bearing temperatures, and magnetic bearing temperatures were monitored throughout the test. Figure 8 shows rotor position (a) and current usage (b) at the high temperature and speed operating condition. From this figure, it can be seen that stable rotor position was achieved with limited work from the magnetic bearing (low current usage). 


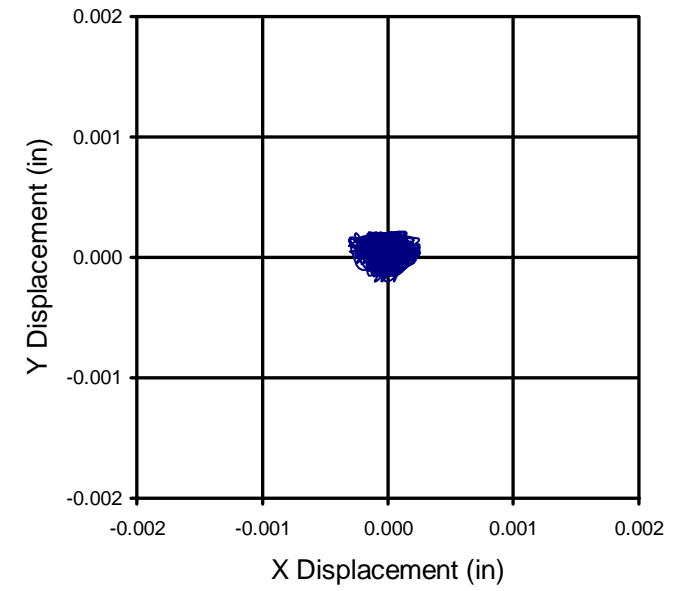

(a)

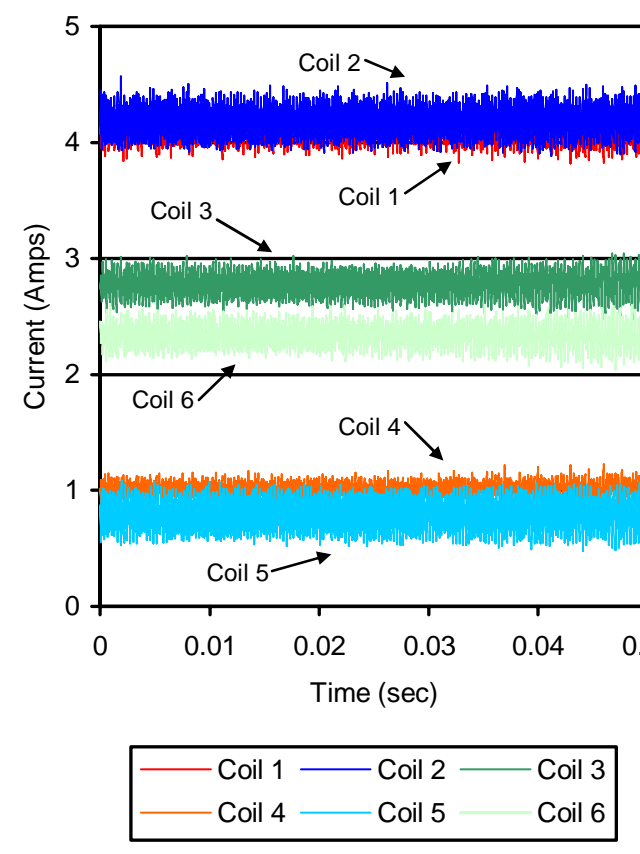

(b)

Figure 8 - Position (a) and current (b) data for 30,000 RPM, $540^{\circ} \mathrm{C}$ $\left(1000^{\circ} \mathrm{F}\right)$ operation of magnetic/hydrostatic rotor support system

\section{CONCLUSIONS}

A high temperature, fault tolerant magnetic rotor support system has successfully been demonstrated. This magnetic bearing is able to compensate for rotor imbalance forces and actively control bearing parameters such as stiffness and damping. A novel backup bearing using a high lubricity material to form a hydrostatic system was also successfully implemented. The complete system operated to 30,000 RPM (2.25 million $\mathrm{DN})$ and $540^{\circ} \mathrm{C}\left(1000^{\circ} \mathrm{F}\right)$.

\section{FUTURE WORK}

This work demonstrated a fully functional, high load, high temperature radial magnetic bearing. In order to help qualify the technology for flight, further research will be done into the long term durability of the bearing. Thermal cycle testing and extended duration tests at high temperature on the mechanical and magnetic properties of the Hyperco $50 \mathrm{HS}$ will be investigated. Testing of a high temperature magnetic thrust bearing that can operate to the same conditions as this radial bearing is scheduled to begin in early 2004 .

Preliminary designs of an engine simulator rig (ESR) that would incorporate this technology have been finished. This rig will extend the technology demonstrated in this paper to a higher speed (4 million DN), large system that is fully supported by magnetic bearings. This rig will have the capacity to simulate an engine environment in terms of temperature and external vibrations (such as wing interactions). Also, the control software is always under development. The system demonstrated used a fairly simple PID type controller. Future controllers will intelligently and automatically adjust bearing parameters to optimize performance. These advancements will make the bearing even more robust and place magnetic bearings on the forefront of next generation technology for intelligent turbomachinery.

\section{REFERENCES}

1) Wesoky, H., 1998, "Environment Goals: Emissions and Noise Aeronautics \& Space Transportation Technology: Three Pillars for Success", $3^{\text {rd }}$ Workshop on NASA's Environmental Compatibility Research.

2) Zaretsky, E.V., Bamberger, E.N., Singer, H., 1974, "Operating Characteristics of $120 \mathrm{~mm}$ Bore Ball Bearings at $3 \times 10^{6} \mathrm{DN}$ ”, NASA TN D-7837.

3) Hibner, Bansal, 1991, "Magnetic Bearing Feasibility and Development”, WL-TR-91-2040.

4) Beams, J.W., Black, S.A., 1939, "Electrically-Driven, Magnetically Supported, Vacuum Type Ultracentrifuge”, 10, pp 59-63, Feb. 1939.

5) Kueser, P.E., Pavlovic, D.M., Lane, D.H., Clark, J.J., Spewock, M., 1967, "Properties of Magnetic Materials for use in HighTemperature Space Power Systems”, NASA SP-3043.

6) Fingers, R.T., 1999, "Creep Behavior of Thin Laminates of Iron Cobalt Alloys for Use In Switch Reluctance Motors and Generators”, AFRL-PR-WR-TR-199-2053.

7) Scholten, J.R., 1997, “A Magnetic Bearing Suspension System for High Temperature Gas Turbine Applications: Control System Design”, International Gas Turbine and Aeroengine Congress and Exhibition.

8) Mekhiche, M. et al., 2000, “ 50,000 RPM, 1,100 F Magnetic Bearings for Jet Turbine Engines”, $7^{\text {th }}$ Inter. Symp. On Magnetic Bearings.

9) Xu, L., Wang, L., Schweitzer, G., 2000, "Development of Magnetic Bearings for High Temperature Suspension”, $7^{\text {th }}$ Inter. Symp. On Magnetic Bearings.

10) Montague, G., Jansen, M.J., Provenza, A., Jansen R.H., Ebihara, B., Palazzolo, A., 2002, "Room Temperature Characterization of Magnetic Bearing for Turbomachinery", NASA/TM-2002211904. 
11) Montague, G., Jansen, M.J., Provenza, A., Palazzolo, A., Jansen, R.H., Ebihara, B., 2003, "Experimental High Temperature Characterization of a Magnetic Bearing for Turbomachinery”, Proc. AHS $59^{\text {th }}$ Inter. Conf.

12) Provenza, A.J., Montague, G.T., Jansen, M.J., Palazzolo, A., Jansen, R.H., 2003, "High Temperature Characterization of a Radial Magnetic Bearing for Turbomachinery”, Proc. ASME/IGTI Turbo Expo 2003.

13) Montague, G., Jansen, M.J., Ebihara, B., Jansen R.H., Palazzolo, A., Tucker, R., Preuss, J., Hunt, A., Trudell, J., Provenza, A., 2003, "Design and Fabrication of a High Temperature Radial Magnetic Bearing for Turbomachinery”, NASA/TM-2003212300.

14) Kaman Instrumentation data sheet, 2004, http://www.kamansensors.com/html/core.htm (Accessed 29, November 2003).
15) Na, Uhn Joo, Palazzolo, A.B., Provenza, A.J., 2002, “Test and Theory Correlation Study for a Flexible Rotor on Fault-Tolerant Magnetic Bearings”, J. of Vib. And Acoustics, 124, pp. 359-366.

16) Na, Uhn Joo, Palazzolo, A.B., 2002, "Optimized Realization of Fault-Tolerant Heteropolar Magnetic Bearings”, J. of Vib. And Acoustics, 122, pp. 209-222.

17) Hibbs R., Scharrer J., Pelfry P., 1995, "Pressure Tap Effects on the Dynamic Characteristics of a Cryogenic Hydrostatic Journal Bearing", $31^{\text {st }}$ AIAA/ASME/SAE/ASEE Joint Propulsion Conference, AIAA-95-2965.

18) Pelfry P., Sishtla V., 1996, "Investigation of Hydrostatic Bearings Operating in a Turbulent, Compressible Liquid”, $32^{\text {nd }}$ AIAA/ASME/SAE/ASEE Joint Propulsion Conference, AIAA-963103. 
Public reporting burden for this collection of information is estimated to average 1 hour per response, including the time for reviewing instructions, searching existing data sources, gathering and maintaining the data needed, and completing and reviewing the collection of information. Send comments regarding this burden estimate or any other aspect of this collection of information, including suggestions for reducing this burden, to Washington Headquarters Services, Directorate for Information Operations and Reports, 1215 Jefferson Davis Highway, Suite 1204, Arlington, VA 22202-4302, and to the Office of Management and Budget, Paperwork Reduction Project (0704-0188), Washington, DC 20503.

\begin{tabular}{|l|l|l|}
\hline 1. AGENCY USE ONLY (Leave blank) & $\begin{array}{c}\text { 2. REPORT DATE } \\
\text { March } 2004\end{array}$ & $\begin{array}{r}\text { 3. REPORT TYPE AND DATES COVERED } \\
\text { Technical Memorandum }\end{array}$ \\
\hline
\end{tabular}

\section{TITLE AND SUBTITLE}

5. FUNDING NUMBERS

High Speed, High Temperature, Fault Tolerant Operation of a Combination

Magnetic-Hydrostatic Bearing Rotor Support System for Turbomachinery

\section{AUTHOR(S)}

Mark Jansen, Gerald Montague, Andrew Provenza, and Alan Palazzolo

\section{PERFORMING ORGANIZATION NAME(S) AND ADDRESS(ES)}

National Aeronautics and Space Administration

John H. Glenn Research Center at Lewis Field

Cleveland, Ohio 44135-3191

WBS-22-714-70-10

1L162211A47A
9. SPONSORING/MONITORING AGENCY NAME(S) AND ADDRESS(ES)

National Aeronautics and Space Administration

Washington, DC 20546-0001

and

U.S. Army Research Laboratory

Adelphi, Maryland 20783-1145
8. PERFORMING ORGANIZATION REPORT NUMBER

E-14391

\section{SUPPLEMENTARY NOTES}

Prepared for the Turbo Expo 2004 sponsored by the American Society of Mechanical Engineers, Vienna, Austria, June 14-17, 2004. Mark Jansen, University of Toledo, Toledo, Ohio 43606; Gerald Montague, U.S. Army Research Laboratory, NASA Glenn Research Center; Andrew Provenza, NASA Glenn Research Center; and Alan Palazzolo, Texas A\&M University, College Station, Texas 77843. Responsible person, Mark Jansen, organization code 5960, 216-433-6054.

12a. DISTRIBUTION/AVAILABILITY STATEMENT

12b. DISTRIBUTION CODE

Unclassified - Unlimited

Subject Category: 07

Distribution: Nonstandard

Available electronically at http://gltrs.grc.nasa.gov

This publication is available from the NASA Center for AeroSpace Information, 301-621-0390.

\section{ABSTRACT (Maximum 200 words)}

Closed loop operation of a single, high temperature magnetic radial bearing to 30,000 RPM (2.25 million DN) and $540{ }^{\circ} \mathrm{C}\left(1000^{\circ} \mathrm{F}\right)$ is discussed. Also, high temperature, fault tolerant operation for the three axis system is examined. A novel, hydrostatic backup bearing system was employed to attain high speed, high temperature, lubrication free support of the entire rotor system. The hydrostatic bearings were made of a high lubricity material and acted as journal-type backup bearings. New, high temperature displacement sensors were successfully employed to monitor shaft position throughout the entire temperature range and are described in this paper. Control of the system was accomplished through a stand alone, high speed computer controller and it was used to run both the fault-tolerant PID and active vibration control algorithms.

\section{SUBJECT TERMS} 15. NUMBER OF PAGES

Turbomachinery; Magnetic bearing; Hydrostatic bearing; High temperature

\section{SECURITY CLASSIFICATION OF REPORT}

Unclassified

\section{SECURITY CLASSIFICATION OF THIS PAGE \\ Unclassified}

19. SECURITY CLASSIFICATION OF ABSTRACT

Unclassified 